\title{
Towards a definition of refractory neuropathic pain for epidemiological research. An international Delphi survey of experts
}

\author{
Blair H Smith ${ }^{1 *}$, Nicola Torrance ${ }^{1}$, Janice A Ferguson ${ }^{1}$, Michael I Bennett ${ }^{2}$, Michael G Serpell ${ }^{3}$ and Kate M Dunn ${ }^{4}$
}

\begin{abstract}
Background: Best current estimates of neuropathic pain (NeuP) prevalence come from studies using various screening detecting pain with probable neuropathic features; the proportion experiencing significant, long-term NeuP, and the proportion not responding to standard treatment are unknown. These "refractory" cases are the most clinically important to detect, being the most severe, requiring specialist treatment.

Methods: We report an international Delphi survey of experts in NeuP, aiming for consensus on the features required to define, for epidemiological research: (1) neuropathic pain; and (2) when NeuP is "refractory". A webbased questionnaire was developed and data collected from three rounds of questionnaires from nineteen experts.

Results: There was good consensus on essential inclusion of six items to identify NeuP ("prickling, tingling, pins \& needles", "pain evoked by light touch", "electric shocks or shooting pain", "hot or burning" pain, "brush allodynia on self-examination", and "relevant history") and on some items that were non-essential. Consensus was also reached on components of a "refractory NeuP" definition: minimum duration (one year); number of trials of drugs of known effectiveness (four); adequate duration of these trials (three months / maximum tolerated); outcomes of treatment (pain severity, quality of life). Further work needs to validate these proposed criteria in general population research.

Conclusions: This paper presents an international consensus on measuring the epidemiology of refractory neuropathic pain. This will be valuable in reaching an agreed estimate of the prevalence of neuropathic pain, and the first estimate of refractory neuropathic pain prevalence.
\end{abstract}

Keywords: Neuropathic pain, Refractory, Epidemiology, Delphi method, Web-based questionnaire

\section{Background}

Studies have examined the prevalence, distribution and determinants of specific conditions associated with neuropathic pain (NeuP), notably postherpetic neuralgia (PHN) and painful diabetic neuropathy (PDN) [1]. However, the overall population prevalence of NeuP remains unknown, and factors associated with its onset and recovery are poorly understood. Prevalence estimates of $1-2 \%[2,3]$ are inaccurate (as they are extrapolated from assumptions relating to specific conditions) and are probably under-estimates [4], as they do not include

\footnotetext{
* Correspondence: b.h.smith@dundee.ac.uk

${ }^{1}$ Medical Research Institute, Mackenzie Building, Kirsty Semple Way,

University of Dundee, Dundee, DD2 4BF, UK

Full list of author information is available at the end of the article
}

undiagnosed NeuP or cases where neuropathic features contribute importantly to pain of mixed mechanism [5].

The current best population estimates for NeuP come from studies using screening instruments that detect pain with probable neuropathic features. One of these, using the S-LANSS, found a prevalence of "pain of predominantly neuropathic origin" (POPNO) of 8.2\% [6]. Another, using the DN4, found a prevalence of "chronic pain with neuropathic characteristics" of 6.8\% [7]. Using the PainDETECT questionnaire, Freynhagen et al [8] estimated that $11.4 \%$ of males had low back pain with a predominantly neuropathic component. Differences in these and other estimates are partly accounted for by differences in the way in which NeuP is defined by the different instruments, which were originally defined for clinical purposes [9]. Whilst there is no ideal epidemiological method for

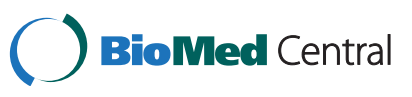


defining and ascertaining NeuP, it is clear that specialist examination is impractical in large population studies, and other methods, such as reviewing medical records, are reliant on the quality and standard criteria of routine data entry. There is therefore a need for consensus on a definition of NeuP for use in population research.

\section{Neuropathic pain that is refractory to treatment}

Among these relatively high reported prevalences, it is unknown what proportion of individuals experience clinically significant, long-term pain and/or pain that has not responded to standard non-specialist treatment. These "refractory" cases of NeuP are clinically the most important to detect, as they are likely to be the most severe and difficult to treat, use healthcare services more often, and to be those who merit informed treatment and follow-up targeted at NeuP. The term "refractory neuropathic pain" has emerged recently in the literature, [10-12] but definitions vary markedly. In a preliminary attempt to review the epidemiology of refractory NeuP, Taylor [12] used a search strategy with a broad definition that included specific named NeuP conditions and pain that was "persistent". The Scottish Medicines Consortium (SMC) describes patients with refractory NeuP as those who "have not achieved adequate pain relief from, or have not tolerated, conventional first and second line treatments for neuropathic pain”, with specific prescribing implications [13]. In one randomised controlled trial [11], refractory NeuP was defined as having had lasted at least six months, with a pain severity score of at least $40 \mathrm{~mm}$ on a $0-100 \mathrm{~mm}$ visual analogue scale, and exhibiting no response to usual pharmacological care. There is, however, neither consensus on these definitions, nor critical review of their parameters.

Hansson et al. recently proposed a definition of "pharmacoresistant" NeuP and a rational approach to prescribing efficacious drugs in order of precedence [14]. However, the authors concluded that the required scientific evidence to confirm this definition is not yet available. Furthermore, "refractory NeuP" and "pharmacoresistant NeuP" may be clinically different entities. Attempts to distinguish between refractory and pharmacoresistant epilepsy have proved challenging $[15,16]$, with no final consensus.

If refractory NeuP can be defined and classified in a way that is agreed to be clinically and epidemiologically relevant, it will be possible to identify individuals and sub-groups within the community who experience this most severe NeuP and are in greatest need of treatment. This will in turn allow an assessment of the scale of the problem, identification of risk factors for "refractoriness" (including those that are potentially modifiable), and the subsequent efficient targeting of management or prevention strategies.
The aims of this study were therefore to reach expert consensus on the features required to define, for epidemiological research: (1) neuropathic pain; and (2) when neuropathic pain is "refractory". These features should be able to be incorporated into a questionnaire suitable for administration to large study samples.

\section{Methods}

\section{Consensus of experts/the Delphi method}

The Delphi technique has been used widely in medical and nursing research as a survey method used to gain consensus among a group of respondents [17-19]. The technique involves asking a panel of experts to take part in a series of consecutive rounds of questionnaires designed to achieve increasing consensus of opinion. A panel usually consists of 15 to 30 participants [18], between 12 and 20 being considered optimal [18,20]. Typically three rounds of questionnaires are sent to the expert panel, although the decision over the number of rounds is largely pragmatic and often varies between two and four partly depending on the quality and rates of response [20-22]. Participants' responses are anonymised to ensure that the influence of peer pressure on respondents' opinions is minimised [23]. A summary of the results showing the distribution of the group's response and patterns of agreement of the previous round are fed back to be evaluated by panel members $[19,23]$. Consensus can be said to be achieved when a given proportion of participants are in agreement. This proportion varies between studies, with some authors accepting $51 \%$ [24] whilst other have suggested levels of between $60 \%$ and $80 \%$ are required [17,25-27].

\section{Participants}

Internationally recognised experts on neuropathic pain research were identified. These included authors of important published epidemiological and clinical studies, and members of the Committee of the Neuropathic Pain Special Interest Group (NeuP SIG) of the International Association for the Study of Pain, who developed guidelines on the assessment of neuropathic pain [28]. These individuals were approached by email with an invitation to participate in the Delphi method survey. The final list included 40 experts from 11 countries. To comply with the conditions of ethical approval, the identities of experts were kept confidential throughout the study and beyond. We set a priori the level of agreement between them at which consensus would be recognized as $70 \%$, recognizing that more than a simple majority would be required but that the complexity of the concepts involved meant that greater agreement might be unfeasible, or exclude a meaningful definition. Similarly, less than $30 \%$ agreement was considered to represent consensus about excluding items. 


\section{First round}

A web-based questionnaire was developed using SurveyMonkey (http://www.surveymonkey.com ). Each expert was sent an email inviting them to take part in the study and a link to access the questionnaire on the SurveyMonkey website.

In this round, we asked about the usefulness of items found in published screening tools developed to identify pain with neuropathic characteristics [29], and which of these individual items "should be included in an instrument to be utilised in epidemiological research". Participants were to choose whether items were essential to include, not essential to include, or whether items should not be included. They were also asked to specify any other essential items.

A further free text question asked participants "In your opinion, when does neuropathic pain become "refractory"? Please list the crucial features that you consider would categorise a patient as having "refractory neuropathic pain".

\section{Second round}

The results of round one were fed back to each of the participants by email, along with a link to the round 2 questionnaire. This questionnaire asked participants to consider their agreement about the inclusion of all of the items that were included in round 1 . Content analysis of the free text responses to the question on the features that characterise refractory NeuP was conducted to identify common attributes to be included in a possible definition. The attributes that were identified were: "Minimum duration of neuropathic pain", "Number of drugs of known effectiveness for neuropathic pain tried", "What might comprise an adequate trial for neuropathic pain treatment?", "Outcome of treatment" and "Usefulness of other non-drug therapies". Specific levels within each of these attributes were also generated from the free text responses (shown in Table 1).

Agreement was sought (from $1=$ strongly agree to 5 = strongly disagree) on whether individual items should be included in the definition of neuropathic pain, and for each of the attributes that might determine when this was refractory.

Finally, we asked about any perceived difference between the terms "Refractory Neuropathic Pain" and "Pharmacoresistant Neuropathic Pain", and whether participants had any preferred terms or further comments about the study.

\section{Third round}

Individual and group responses were fed back to each participant and they were asked for a final time to indicate their level of agreement with each of the components to be incorporated into a working definition of refractory neuropathic pain.

\section{Ethical approval}

This study was approved by Ethics Review Board of the College of Life Sciences and Medicine, University of Aberdeen.

\section{Results}

Of the forty invited experts, six indicated that they were not eligible for the study. Twenty-five of the other experts (73.5\%) completed the Round 1 questionnaire. Response rates throughout each round of the study are shown in Figure 1. In total nineteen experts returned completed questionnaires for all three rounds of the Delphi survey. No further participants were sought as the sample had achieved an "optimal size" for a Delphi study $[18,20]$. Participants in round one $(n=25)$ represented a range of medical and research disciplines (including neurology, epidemiology, anaesthetics, pain medicine, and neuropharmacology) and were based in nine countries (thirteen were from the UK, seven participants were from five other European countries, four were from North America and one from Australasia).

Items to be included in the definition of neuropathic pain The level of agreement after three rounds for items to be included in a case definition instrument for neuropathic pain in epidemiology research is shown in Figure 2. There was consensus (with at least $70 \%$ of participants agreeing or strongly agreeing) that six items about the presence of pain with the following characteristics should be included: "prickling, tingling, pins \& needles", "pain evoked by light touch", "electric shocks or shooting pain", "hot or burning" pain, "a relevant patient history", and "brush allodynia on self-examination". There was consensus (less than 30\% agreeing or strongly agreeing) that eleven items should not necessarily be included. A further six items produced mixed responses and considerable uncertainty about their inclusion (Table 2).

\section{Definitions of refractory neuropathic pain}

All participants in Round 1 completed the question about when neuropathic pain becomes "refractory neuropathic pain". Some examples of the free text responses are shown in Table 3. Content analysis of all of the responses enabled attributes and levels to be identified for incorporation into the Round 2 questionnaire (see above).

\section{Minimum duration of neuropathic pain}

There was no clear agreement on the minimum duration of NeuP for it to become refractory (Table 1, Figure 3a). However, there was clear consensus that three months was an insufficient period of time, as 17/19 (89.5\%) of the experts disagreed or strongly disagreed that NeuP could be said to be refractory after this length of time. 
Strongest agreement was for greater than one year, but many $(8 / 19,42.1 \%)$ considered that duration was not relevant to determining refractory neuropathic pain (Table 1, Figure 3a).
Number of drugs of known effectiveness for neuropathic pain tried

There was good agreement that four $(16 / 18,89 \%$ of participants strongly agreed/ agreed), or more than four

Table 1 Attributes and levels identified for consideration in determining refractoriness of neuropathic pain, and subsequent consensus among participants

\begin{tabular}{|c|c|c|c|c|}
\hline & Median $(/ 5)^{*}$ & Mean* & $\begin{array}{l}\text { Level of consensus, } \% \\
\text { (n) }\end{array}$ & $\begin{array}{c}\text { Final consensus on } \\
\text { inclusion/exclusion }(>70 \%)\end{array}$ \\
\hline \multicolumn{5}{|l|}{ Minimum duration of NeuP } \\
\hline Three months & 4.00 & 4.05 & $\begin{array}{l}89.5 \%(17) \text { disagree/ } \\
\text { strongly disagree }\end{array}$ & YES \\
\hline Six months & 3.00 & 2.89 & $\begin{array}{l}36.8 \%(7) \text { strongly agree/ } \\
\text { agree }\end{array}$ & NO \\
\hline More than one year & 2.00 & 2.53 & $\begin{array}{l}52.6 \%(10) \text { strongly } \\
\text { agree/agree }\end{array}$ & NO \\
\hline Duration irrelevant & 3.00 & 3.05 & $\begin{array}{l}42.1 \%(8) \text { strongly agree/ } \\
\text { agree }\end{array}$ & NO \\
\hline \multicolumn{5}{|l|}{$\begin{array}{l}\text { Minimum number of drugs of known effectiveness for } \\
\text { NeuP tried }\end{array}$} \\
\hline Two drugs & 4.00 & 3.83 & $\begin{array}{l}72.2 \%(13) \text { disagree/ } \\
\text { strongly disagree }\end{array}$ & YES \\
\hline Three drugs & 2.00 & 2.44 & $\begin{array}{l}66.7 \%(12) \text { strongly } \\
\text { agree/agree }\end{array}$ & NO \\
\hline Four drugs & 2.00 & 1.78 & $\begin{array}{l}88.9 \%(16) \text { strongly } \\
\text { agree/agree }\end{array}$ & YES \\
\hline More than four drugs & 1.00 & 1.39 & $\begin{array}{l}94.5 \%(17) \text { strongly } \\
\text { agree/agree }\end{array}$ & YES \\
\hline \multicolumn{5}{|l|}{ An adequate trial of NeuP treatment } \\
\hline One week & 5.00 & 4.78 & $\begin{array}{l}100 \% \text { (18) disagree/ } \\
\text { strongly disagree }\end{array}$ & YES \\
\hline One month & 3.00 & 3.17 & $\begin{array}{l}31.6 \%(6) \text { strongly agree/ } \\
\text { agree }\end{array}$ & NO \\
\hline Three months & 2.00 & 2.06 & $\begin{array}{l}83.5 \%(15) \text { strongly } \\
\text { agree/agree }\end{array}$ & YES \\
\hline Until adverse effects prevent adequate dosage & 1.00 & 1.63 & $\begin{array}{l}89.5 \%(17) \text { strongly } \\
\text { agree/agree }\end{array}$ & YES \\
\hline \multicolumn{5}{|l|}{ Outcomes of pain treatment } \\
\hline Pain levels of 5 or more on a $0-10$ pain scale & 2.00 & 2.61 & $\begin{array}{l}83.3 \%(15) \text { strongly } \\
\text { agree/agree }\end{array}$ & YES \\
\hline Less than $30 \%$ pain intensity reduction & 2.00 & 2.06 & $\begin{array}{l}88.9 \%(16) \text { strongly } \\
\text { agree/agree }\end{array}$ & YES \\
\hline No period of pain remission & 2.00 & 2.12 & $\begin{array}{l}82.4 \%(14) \text { strongly } \\
\text { agree/agree }\end{array}$ & YES \\
\hline An increase in pain severity & 2.00 & 1.78 & $\begin{array}{l}77.8 \%(14) \text { strongly } \\
\text { agree/agree }\end{array}$ & YES \\
\hline $\begin{array}{l}\text { Quality of life remains significantly affected by pain } \\
\text { (e.g. sleep, activity limitations, mood, disability) }\end{array}$ & 2.00 & 1.83 & $\begin{array}{l}83.3 \%(15) \text { strongly } \\
\text { agree/agree }\end{array}$ & YES \\
\hline \multicolumn{5}{|l|}{ Usefulness of other non-drug therapies } \\
\hline $\begin{array}{l}\text { Non-pharmacological therapies must be tried before } \\
\text { neuropathic pain is considered refractory (e.g. TNS, physical } \\
\text { therapy, psychological therapy, relaxation) }\end{array}$ & 2.00 & 2.58 & $\begin{array}{l}63.2 \%(12) \text { strongly } \\
\text { agree/agree }\end{array}$ & NO \\
\hline No response to spinal cord stimulator & 4.00 & 3.89 & $\begin{array}{l}73.7 \%(14) \text { disagree/ } \\
\text { strongly disagree }\end{array}$ & YES \\
\hline
\end{tabular}




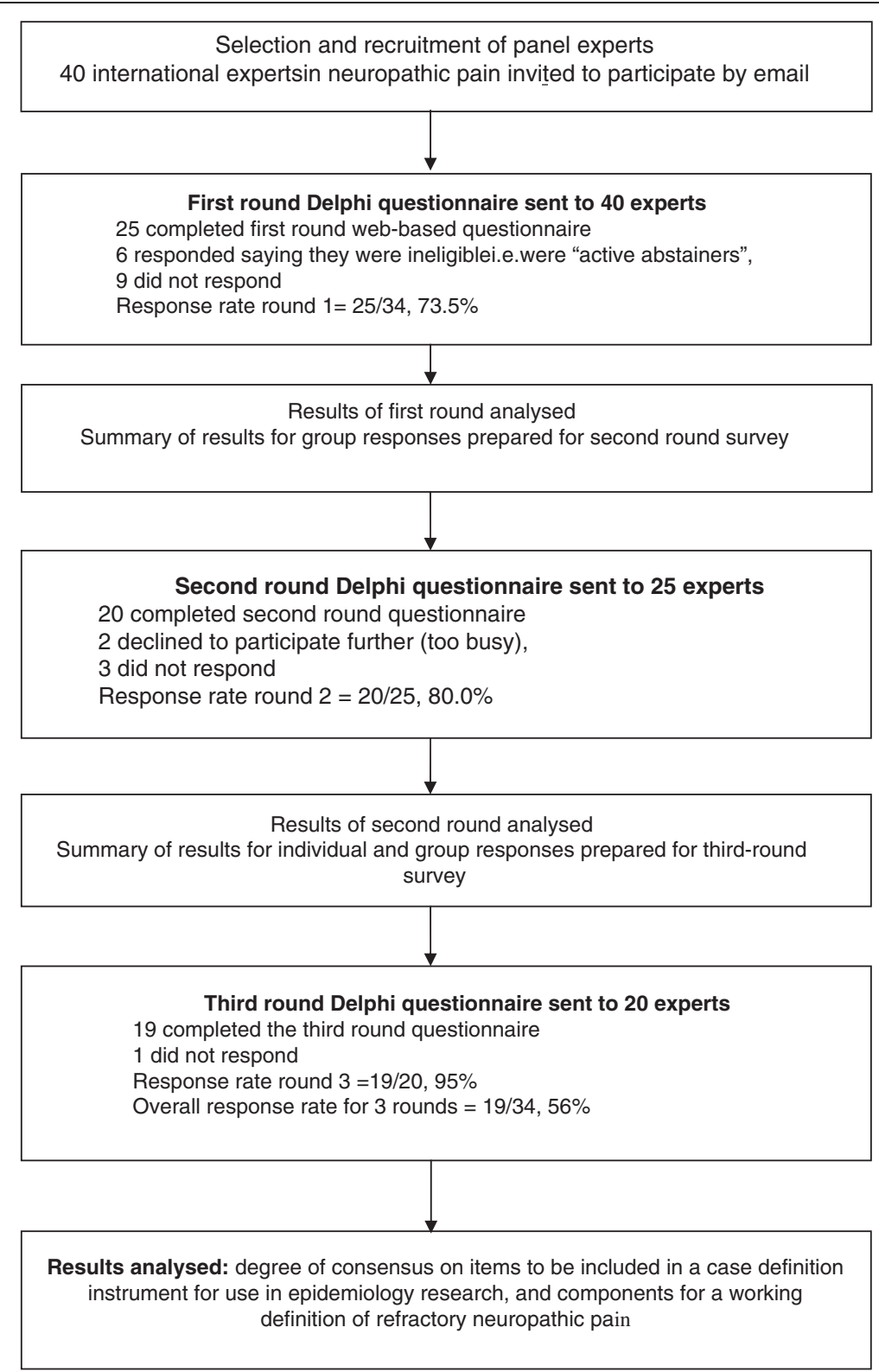

Figure 1 Flowchart of participants in the study.

drugs $(17 / 18,94.5 \%$ of participants strongly agreed/ agreed) of known effectiveness for neuropathic pain had to be tried before it became "refractory" (Table 1 / Figure 3b). Two thirds of participants indicated that a trial of three neuropathic pain drugs was sufficient, and there was consensus (13/18, 72.2\% disagreed/strongly disagreed) that two drugs were insufficient.

\section{An adequate trial of neuropathic pain treatment}

There was consensus that at least three months' trial of each neuropathic pain treatment was necessary $(15 / 18$, $83.3 \%$ of participants), or treatment until adverse effects prevented adequate dosage (17/19, $89.4 \%$ of participants) before it could be considered refractory.

\section{Outcome of treatment}

There was consensus that any of the listed outcomes of treatment was sufficient to render neuropathic pain refractory: persistence of pain, failure to reduce pain intensity or severity significantly, an increase in pain severity, or persistently reduced quality of life (Figure 3d).

\section{Usefulness of other non-drug therapies}

Although 12/19 (63\%) participants agreed that nonpharmaceutical therapies (included therapies such as 


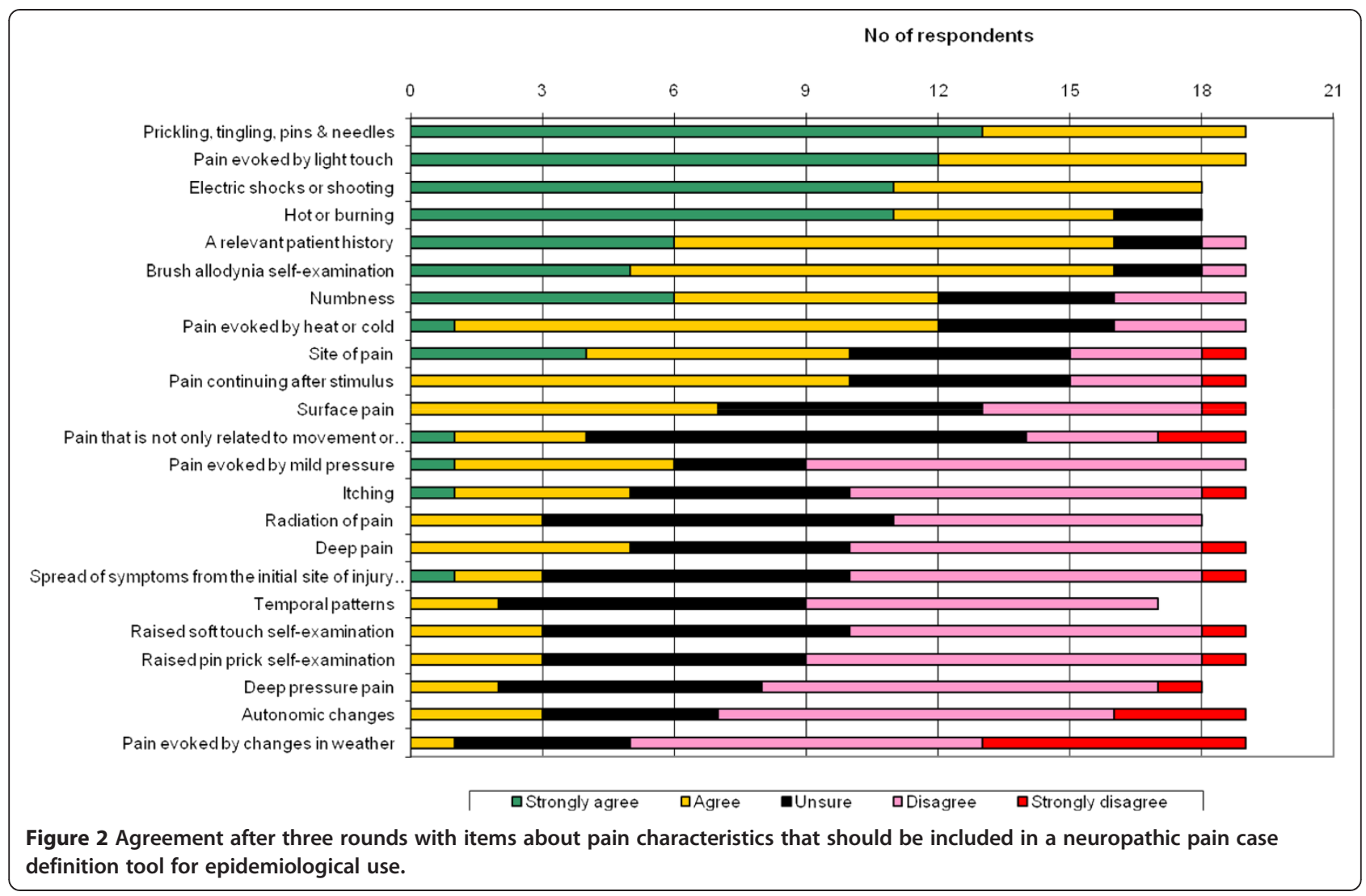

transcutaneous nerve stimulation, physical therapy, psychological therapy, relaxation) should be tried before neuropathic pain is considered refractory, this response did not meet the consensus level (of 70\%). There was, though, consensus $(14 / 19,73.7 \%)$ that trial of spinal cord stimulation was not required before NeuP could be considered refractory.

\section{Terminology}

Sixteen participants (84.2\%) agreed or strongly agreed that there was a difference between the terms "Refractory Neuropathic Pain" and "Pharmacoresistant Neuropathic Pain", with many comments suggesting that both terms were important in their own right.

\section{Discussion}

This study aimed to achieve consensus from an international group of experts in neuropathic pain epidemiology on (1) the components of a questionnaire instrument for identifying neuropathic pain in epidemiology research, and (2) when this pain could be termed "refractory". Lack of consensus in the first of these has hindered epidemiology research to date, and contributed to the considerable variance in published prevalence rates. This was not intended to supplant the clinical definition of (possible) NeuP [30], but to allow this to be partly operationalised in population-based research. There has previously been no consensus on refractoriness, despite several publications purporting to report on refractory neuropathic pain.

\section{Identifying neuropathic pain}

In summary, we found that a case definition instrument for neuropathic pain should certainly include five questions about pain characteristics, and one eliciting a clinical history consistent with neuropathic pain (Table 2). An additional six items produced mixed responses from the expert group. Given the need for brevity and focus in most population research questionnaires, we propose that only the six items with $>70 \%$ consensus be included in a standard case definition instrument for epidemiology research. The five characteristics of pain quality identified by survey respondents are all featured within the three most widely used screening tools for neuropathic pain (S-LANSS, DN4, painDETECT) [9,31]. The remaining characteristic (a relevant patient history) does not feature in these screening tools but is part of the diagnostic algorithm advocated by Treede et al [30].

We examined these five characteristics of pain quality against the cut-off scores within each of the screening tools to determine which combination(s) might be used as a case definition tool for epidemiological use: 
Table 2 Case definition items to be included in a questionnaire instrument for epidemiology research

Questions about pain characteristics:

Prickling, tingling, pins and needles

Pain evoked by light touch

Electric shocks or shooting pain

Hot or burning pain

Brush allodynia on self examination

Question eliciting a relevant patient history

Items that might be included (>30\% but $<70 \%$ consensus)

Questions about pain characteristics:

Numbness

Pain evoked by heat or cold

Pain continuing after stimulus

Surface pain

Pain evoked by mild pressure

Question about the site of pain

- DN4: cut-off is score of 4, equivalent to any four items [32].

- S-LANSS: cut-off is score of 12 or more. Of the five possible combinations using four items each, three combinations reach a positive score. The remaining two combinations score 11 [29].

- painDETECT: cut-off score is 13 or more. If three items are rated at least 3 (strongly) and one item 4 (very strongly), a positive score is reached [8].

Based on this analysis, we propose to test the validity of a case definition tool for epidemiological use using any four characteristics of pain quality in combination with questions eliciting 'a relevant patient history'. It is not proposed that this tool would replace detailed history and examination, which must remain as cornerstones in the clinical setting.

\section{Determining refractory neuropathic pain}

For neuropathic pain to be considered refractory, based on the consensus reported above, we propose that:

- It should have had a trial of treatment with at least four drugs of known effectiveness in neuropathic pain

- Each of these drugs should have been tried for at least three months or until adverse effects prevent adequate dosage

- Despite the above treatment, the intensity of pain should have reduced by less than $30 \%$, or should remain at a level of at least 5 on a $0-10$ scale; and/ or it should continue to contribute significantly to poor quality of life.
We propose that the duration of neuropathic pain, by itself does, not determine whether it is refractory (though it is clearly relevant when considering the duration of any trials of treatment). We also propose that, while non-pharmacological treatments should be considered, and may be effective, neuropathic pain can be considered refractory even in their absence.

\section{Strengths and limitations of the study}

Delphi surveys are an established method of achieving consensus in complex areas and/or where consensus has not previously been able to be reached [18]. For example previous studies have used Delphi methods to develop a standard definition for back pain for use in prevalence studies (a consensus of 28 experts in back pain research from 12 countries) [33], and to develop guidelines for the management of hip and knee osteoarthritis (a consensus of 16 experts from four medical disciplines and six countries) [27]. The composition of the expert panel is important, and should comprise a reasonable number of individuals, representing a widespread range of experts in the relevant discipline(s).

The response rate to this international study was good, with participation from 25 (73.5\% of eligible) invited experts in NeuP in round one, and from 19 (76\%) of these experts participating in all three rounds. These included participants from a range of clinical and research disciplines and a number of countries worldwide, all of whom had been previously recognized through international peer selection as experts in their fields. Considerable weight can therefore be given to the items on which clear consensus was achieved. Although the nature of work in this area meant that most of the respondents knew members of the research team, it is unlikely that this would have contributed importantly to any bias in the responses: responses were anonymous, and there appeared to be no hesitation in expressing forthright views. It would have been possible to include more experts, increasing the number of responses and their sources. We were concerned to include individuals who had contributed importantly to the literature in this field, and our sample represents a good selection of these, but it is possible that including experts based in other countries, including the developing world, would have further enriched our responses.

It must be noted, however, that unanimity was not achieved for any item, and there must still be room for flexibility in designing and interpreting questionnaire aiming to identify refractory neuropathic pain. For example, whilst we have proposed that an adequate trial of at least four drugs is required before NeuP should be considered "refractory", good consensus was nearly achieved (66.7\%) on a trial of three drugs. Indeed, two of the experts approached stated their view that it was 


\section{Table 3 A selection of free text responses about a definition of refractory neuropathic pain}

"Pain that cannot be reduced to levels of 4 or less on a 1-10 scale after all available biomedical treatments have been given and adequate try"

"Does not respond to 3 different classes of neuropathic pain drugs (TCA, > gabapentin/ pregabalin/ opioid at established sufficient dose each for a sufficient time"

"Duration $>6$ months and unresponsive or poorly responsive to gabapentin/ pregabalin, TCA, topical lidocaine patch, opioid"

"Persistent clinical relevant pain despite a proper trial of gabapentin or pregabalin and a tricyclic antidepressant or a serotonin noradrenalin reuptake inhibitor"

"When, after appropriate assessment and treatment, patients are still often distressed and/or have activity limitations due to their NP, and also have persistent symptoms of the type outlined above"

"Persists more than a year after original injury or lesion. Pain levels greater than 5/10 despite adequate trial with standard class 1 or 2 drugs. Pain significantly affects the quality of life, sleep and daily function despite adequate therapy with pharmacological agents, physical therapy and CAM therapies"

"Patients got insufficient pain relief after trying Pregabalin up to $450 \mathrm{mg} /$ die, amitriptyline $1 \mathrm{mg}$ per kilo, oxycodone $20 \mathrm{mg}$, or could not reach the target dosage because of adverse events. If patients have contraindications to a TCA antidepressant they should try duloxetine $60 \mathrm{mg}$ or venlafaxine $225 \mathrm{mg}$. If patients have allodynia in a small area they should also try a lidocaine patch. If patients have Trigeminal neuralgia they should try none of the above; they should try oxcarbazepine up to $1600 \mathrm{mg}$ or carbamazepine up to $1000 \mathrm{mg}$. If they can reach adequate dosage with either drug and still get insufficient pain relief they should be proposed surgery. Concerning the problem of combination therapy, I do not think we have enough evidence to ask for it. Perhaps it may be considered when adverse events prevent reaching the adequate dosage?"

"6 months history not responded to first line treatments (ie medication with lidocaine, anticonvulsants, antidepressants) significant disability and distress"

"All of the neuropathic pain beyond 3 months is chronic and all of the neuropathic pain that persists at level of 5/10 or higher even with a single or multiple treatment modalities is refractory"

"Resistant to any kind of pharmacological and nonpharmacological therapy, if the drugs and doses have been tested along the common guidelines (long and high enough)"

inadvisable to try to identify neuropathic pain through a questionnaire, preferring instead a clinical assessment. We recognise the distinction between diagnosing neuropathic pain using clinical assessment in order to initiate treatment, and estimating the likelihood of neuropathic pain in a population using proxy criteria in order to understand epidemiological factors. Whilst we respect the importance of rigorous clinical examination in providing a detailed assessment of neuropathic pain, we maintain that this is not practical for research in studies of the sample size required for accurate epidemiology. We are not proposing the above case definition questionnaire as a "gold standard" for neuropathic pain, but as a rigorous consensus, for research purposes only, which may now be tested in the field. Clinical examination is required to identify and assess "definite" neuropathic pain [30], (though this, too, must be based on consensus [28] rather than any "gold standard"). It is likely that our questionnaire will be capable of approximating "possible" neuropathic pain in large samples [30].

\section{Implications of the findings}

It is anomalous that, while there was strong consensus that "refractory" and "pharmacoresistant" neuropathic pain are different from each other, there was consensus (84\%) on the definition of "refractory" neuropathic pain. Although the a priori level of $70 \%$ consensus was not achieved for the importance of trying non-pharmacological treatments, agreement approached this (63\%), and free text comments supported it, and these treatments are therefore likely to represent the main difference between these two concepts. Psychological treatments and pain management programme, for example, may be effective in neuropathic pain $[34,35]$. Although "pharmacoresistant" neuropathic pain is not itself a consensus term, as our "refractory" neuropathic pain is, it is based on international consensus of a treatment paradigm of efficacious drugs $[14,36]$.

These and other consensuses on pharmacological treatment, [36-39] provide an excellent basis on which clinicians can determine the order and nature of drugs to be used in neuropathic pain. Importantly, they also provide a framework for inquiring about treatment trials in epidemiology research. Whereas most of these focus on treatment in specialist settings, the recent guidelines from the National Institute for Health and Clinical Excellence (NICE) in the UK [39] focused on the non-specialist setting. The recommendations in the NICE guideline are broadly consistent with determining refractoriness at the point of specialist referral (that is, after a trial of three or four effective drugs).

It is important, as a far as possible, to use standard definitions and tools in research, including epidemiology. Good epidemiology provides a foundation basis for identifying resource, educational, treatment and prevention strategies, and for the subsequent evaluation of these. The use of standard tools allows comparison between different geographical areas, clinical and demographic subgroups, and periods of time. This study has allowed progress towards this for research on (refractory) neuropathic pain. Further work is now required to validate our proposed criteria in a general population study, and to review results of such a study in comparison with existing data, based on the range of instruments currently available. Our proposals represent a distilled compromise between the best features of existing instruments, with consensus from experts internationally. 


\section{a. Minimum duration of refractory NeuP}

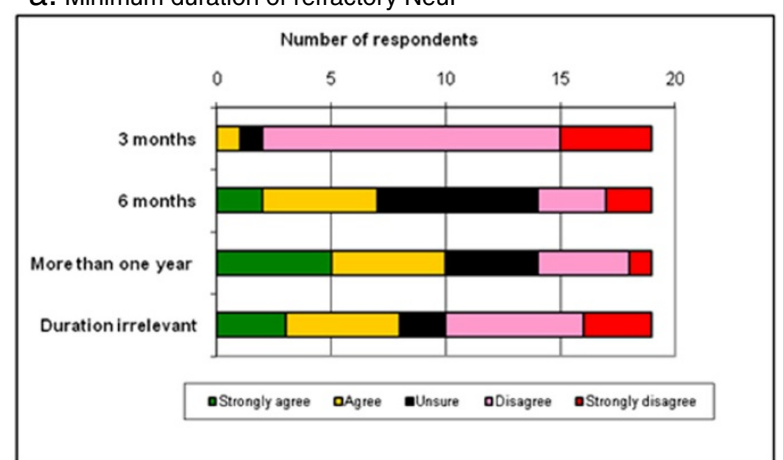

C. Adequate trial of NeuP treatment

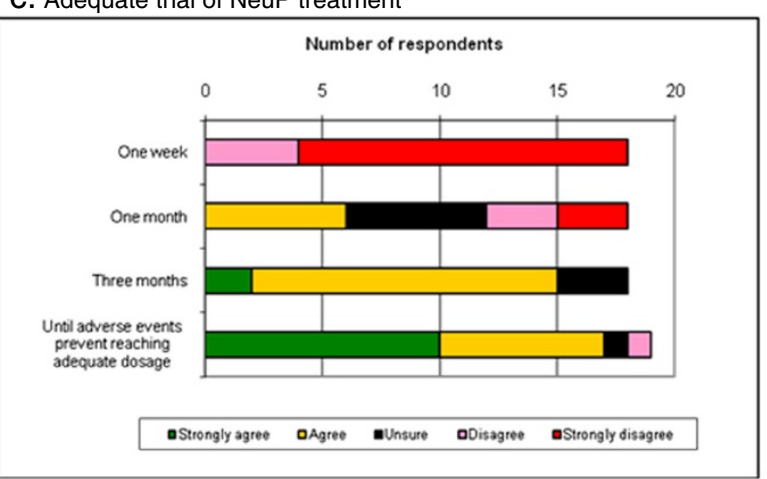

e. Usefulness of non-drug therapies

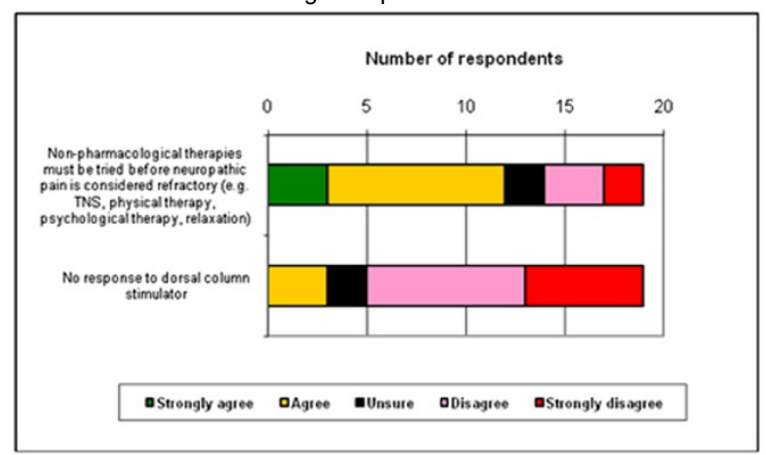

b. Number of drugs of known effectiveness for NeuP that have been tried

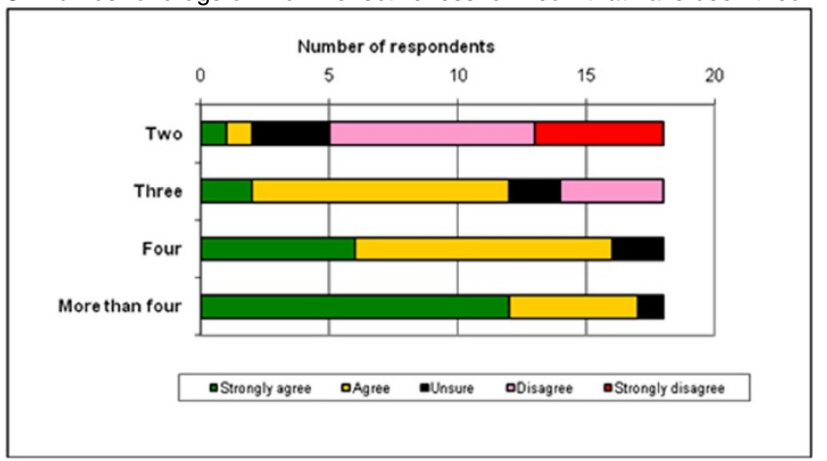

d. Outcomes of NeuP treatment that would make it "refractory"

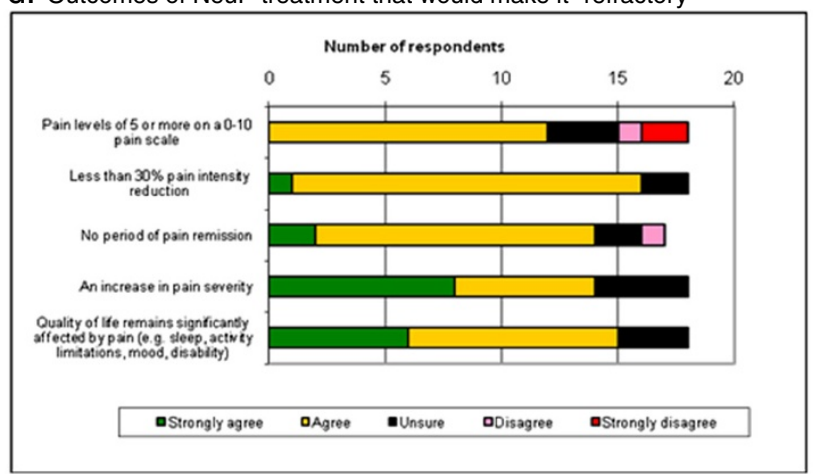

Figure 3 Agreement with levels of attributes identified for a definition of refractory neuropathic pain for use in epidemiology research.

\section{Competing interests}

The authors declare that they have no competing interests.

\section{Authors' contributions}

All lead investigators (BHS, NT, MB, MS, KD) contributed to the conception and design of this study. Data collection and analysis were conducted by JF and NT. All authors were involved in the interpretation of data. BHS lead the writing of this manuscript and produced the first complete draft. All authors contributed to, and commented on all drafts, and approved the final manuscript.

\section{Acknowledgements}

We would like to thank members of the IASP NeuPSIG Committee on the Assessment of Neuropathic Pain, and the other neuropathic pain experts who either contributed, or considered contributing to this study.
The study was funded by an unrestricted educational grant from Pfizer UK Ltd.

\section{Author details}

${ }^{1}$ Medical Research Institute, Mackenzie Building, Kirsty Semple Way, University of Dundee, Dundee, DD2 4BF, UK. ${ }^{2}$ Leeds Institute of Health Sciences International, University of Leeds, Leeds, UK. ${ }^{3}$ Gartnavel General Hospital, University Department of Anaesthesia and Pain Management, Glasgow, UK. ${ }^{4}$ Arthritis Research UK Primary Care Centre, Keele University, Keele, Staffordshire, UK. 


\section{References}

1. Smith BH, Torrance N: Epidemiology of neuropathic pain. Pain Manage 2011, 1:87-96

2. Bennett GJ: Neuropathic pain: an overview. In Molecular Biology of Pain. Edited by Borsook D. Seattle, WA: IASP Press; 1997:109-113.

3. Bowsher D, Rigge M, Sopp L: Prevalence of chronic pain in the British population: a telephone survey of 1037 households. The Pain Clinic 1991, 4:223-230.

4. Dworkin $\mathrm{RH}$ : An overview of neuropathic pain: syndromes, symptoms, signs, and several mechanisms. Clin J Pain 2002, 18:343-349.

5. Bennett Ml, Smith BH, Torrance N, Lee AJ: Can pain be more or less neuropathic? Comparison of symptom assessment tools with ratings of certainty by clinicians. Pain 2006, 122:289-294.

6. Torrance N, Smith BH, Bennett MI, Lee AJ: The epidemiology of chronic pain of predominantly neuropathic origin. Results from a general population survey. J Pain 2006, 7:281-289.

7. Bouhassira D, Lanteri-Minet $M$, Attal N, Laurent B, Touboul C: Prevalence of chronic pain with neuropathic characteristics in the general population. Pain 2008, 136:380-387.

8. Freynhagen R, Baron R, Gockel U, Tolle TR: painDETECT: a new screening questionnaire to identify neuropathic components in patients with back pain. Curr Med Res Opin 2006, 22:1911-1920.

9. Bennett Ml, Bouhassira D: Epidemiology of neuropathic pain: can we use the screening tools? Pain 2007, 132:12-13.

10. Niv D, Devor M: Refractory neuropathic pain: the nature and extent of the problem. Pain Pract 2006, 6:3-9.

11. Stacey BR, Dworkin RH, Murphy K, Sharma U, Emir B, Griesing T: Pregabalin in the treatment of refractory neuropathic pain: results of a 15-month open-label trial. Pain Med 2008, 9:1202-1208.

12. Taylor RS: Epidemiology of refractory neuropathic pain. Pain Pract 2006, 6:22-26.

13. Scottish Medicines Consortium: Pregabalin (Lyrica). Scottish Medicines Consortium advice to NHS Scotland. Briefing note 18 2009, Available at [http://www.scottishmedicines.org.uk/files/briefing-notes/2009/ Briefing note smc May09.pdf Accessed 2nd June 2011].

14. Hansson PT, Attal N, Baron R, Cruccu G: Toward a definition of pharmacoresistant neuropathic pain. Eur J Pain 2009, 13:439-440.

15. Berg AT: Identification of pharmacoresistant epilepsy. Neurol Clin 2009, 27:1003-1013

16. Kwan P, Brodie MJ: Definition of refractory epilepsy: defining the indefinable? Lancet Neurol 2010, 9:27-29.

17. Ferguson FC, Brownlee M, Webster V: A Delphi study investigating consensus among expert physiotherapists in relation to the management of low back pain. Musculoskeletal Care 2008, 6:197-210.

18. Linstone HA, Turoff M: The Delphi Method. Techniques and Applications. Massachussets: Addison-Wesley Publishing Company; 1975.

19. McCarthy CJ, Rushton A, Billis V, Arnall F, Oldham JA: Development of a clinical examination in non-specific low back pain: a Delphi technique. J Rehabil Med 2006, 38:263-267.

20. Payne K, Nicholls SG, McAllister M, Macleod R, Ellis I, Donnai D, Davies LM: Outcome measures for clinical genetics services: a comparison of genetics healthcare professionals and patients' views. Health Policy 2007, 84:112-122.

21. Powell C: The Delphi technique: myths and realities. J Adv Nurs 2003, 41:376-382.

22. Yates SL, Morley S, Eccleston C, de C Williams AC: A scale for rating the quality of psychological trials for pain. Pain 2005, 117:314-325.

23. Jones J, Hunter D: Consensus methods for medical and health services research. BMJ 1995, 311:376-380.

24. Hasson F, Keeney S, McKenna H: Research guidelines for the Delphi survey technique. J Adv Nurs 2000, 32:1008-1015.

25. Boonen A, van Berkel M, Kirchberger I, Cieza A, Stucki G, van der Heijde D: Aspects relevant for functioning in patients with ankylosing spondylitis according to the health professionals: a Delphi study with the ICF as reference. Rheumatol 2009, 48:997-1002.

26. Skjutar A, Christensson K, Mullersdorf M: Exploring indicators for pain rehabilitation: a Delphi study using a multidisciplinary expert panel. Musculoskeletal Care 2009, 7:227-242.

27. Zhang W, Moskowitz RW, Nuki G, Abramson S, Altman RD, Arden N, Bierma-Zeinstra S, Brandt KD, Croft P, Doherty M, Dougados M, Hochberg M, Hunter DJ, Kwoh K, Lohmander LS, Tugwell P: OARSI recommendations for the management of hip and knee osteoarthritis, Part II: OARSI evidence-based, expert consensus guidelines. Osteoarthr Cartil 2008, 16:137-162.

28. Haanpaa M, Attal N, Backonja M, Baron R, Bennett M, Bouhassira D, Cruccu G, Hansson P, Haythornthwaite JA, lannetti GD, Jensen TS, Kauppila T, Nurmikko TJ, Rice AS, Rowbotham M, Serra J, Sommer C, Smith BH, Treede RD: NeuPSIG guidelines on neuropathic pain assessment. Pain 2011, $152: 14-27$.

29. Bennett MI, Smith BH, Torrance N, Potter J: The S-LANSS score for identifying pain of predominantly neuropathic origin: validation for use in clinical and postal research. J Pain 2005, 6:149-158.

30. Treede RD, Jensen TS, Campbell JN, Cruccu G, Dostrovsky JO, Griffin JW, Hansson P, Hughes R, Nurmikko T, Serra J: Neuropathic pain: redefinition and a grading system for clinical and research purposes. Neurology 2008, 70:1630-1635.

31. Bennett Ml, Attal N, Backonja MM, Baron R, Bouhassira D, Freynhagen R, Scholz J, Tolle TR, Wittchen HU, Jensen TS: Using screening tools to identify neuropathic pain. Pain 2007, 127:199-203.

32. Bouhassira D, Attal N, Alchaar H, Boureau F, Brochet B, Bruxelle J, Cunin G, Fermanian J, Ginies P, Grun-Overdyking A, Jafari-Schluep H, Lanteri-Minet M, Laurent B, Mick G, Serrie A, Valade D, Vicaut: Comparison of pain syndromes associated with nervous or somatic lesions and development of a new neuropathic pain diagnostic questionnaire (DN4). Pain 2005, 114:29-36.

33. Dionne CE, Dunn KM, Croft PR, Nachemson AL, Buchbinder R, Walker BF, Wyatt M, Cassidy JD, Rossignol M, Leboeuf-Yde C, Hartvigsen J, Leino-Arjas P, Latza U, Reis S, Gil Del Real MT, Kovacs FM, Oberg B, Cedraschi C, Bouter LM, Koes BW, Picavet HS, van Tulder MW, Burton K, Foster NE, Macfarlane GJ, Thomas E, Underwood M, Waddell G, Shekelle P, Volinn E, Von Korff M: A consensus approach toward the standardization of back pain definitions for use in prevalence studies. Spine 2008, 33:95-103.

34. Daniel HC, Narewska J, Serpell M, Hoggart B, Johnson R, Rice ASC: Comparison of psychological and physical function in neuropathic pain and nociceptive pain: implications for cognitive behavioral pain management programs. Eur J Pain 2008, 12:731-741.

35. Turk DC, Audette J, Levy RM, Mackey SC, Stanos S: Assessment and treatment of psychosocial comorbidities in patients with neuropathic pain. Mayo Clin Proc 2010, 85:S42-S50.

36. Dworkin RH, O'Connor AB, Backonja M, Farrar JT, Finnerup NB, Jensen TS, Kalso EA, Loeser JD, Miaskowski C, Nurmikko TJ, Portenoy RK, Rice AS, Stacey BR, Treede RD, Turk DC, Wallace MS: Pharmacologic management of neuropathic pain: evidence-based recommendations. Pain 2007, 132:237-251.

37. Attal N, Cruccu G, Baron R, Haanpaa M, Hansson P, Jensen TS, Nurmikko T: EFNS guidelines on the pharmacological treatment of neuropathic pain: 2010 revision. Eur J Neurol 2010, 17:1113-e88.

38. Moulin DE, Clark AJ, Gilron I, Ware MA, Watson CP, Sessle BJ, Coderre T, Morley-Forster PK, Stinson J, Boulanger A, Peng P, Finley GA, Taenzer P, Squire P, Dion D, Cholkan A, Gilani A, Gordon A, Henry J, Jovey R, Lynch M, Mailis-Gagnon A, Panju A, Rollman GB, Velly A, Canadian Pain Society: Pharmacological management of chronic neuropathic pain consensus statement and guidelines from the Canadian Pain Society. Pain Res Manag 2007, 12:13-21

39. National Institute for Health and Clinical Excellence (NICE): Clinical Guideline 96. The pharmacological management of neuropathic pain in adults in nonspecialist settings. London: NICE; 2010.

doi:10.1186/1471-2377-12-29

Cite this article as: Smith et al:: Towards a definition of refractory neuropathic pain for epidemiological research. An international Delphi survey of experts. BMC Neurology 2012 12:29. 